\title{
Chemokine-Mediated Migration of Mesencephalic Neural Crest Cells
}

\author{
Francine Rezzoug, Ratnam S. Seelan, Vasker Bhattacherjee, Robert M. Greene, and M. \\ Michele Pisano \\ University of Louisville, Birth Defects Center, Department of Molecular, Cellular and Craniofacial \\ Biology, ULSD, 501 S. Preston St., Louisville, KY - 40292
}

Francine Rezzoug: f0rezz01@louisville.edu; Ratnam S. Seelan: rsseel01@louisville.edu; Vasker Bhattacherjee: quovasker@aim.com; Robert M. Greene:dr.bob.greene@gmail.com; M. Michele Pisano: pisano@louisville.edu

\begin{abstract}
Clefts of the lip and/or palate are among the most prevalent birth defects affecting approximately 7000 newborns in the United States annually. Disruption of the developmentally programmed migration of neural crest cells (NCCs) into the orofacial region is thought to be one of the major causes of orofacial clefting. Signaling of the chemokine SDF-1 (Stromal Derived Factor-1) through its specific receptor, CXCR4, is required for the migration of many stem cell and progenitor cell populations from their respective sites of emergence to the regions where they differentiate into complex cell types, tissues and organs. In the present study, "transwell" assays of chick embryo mesencephalic (cranial) NCC migration and ex ovo whole embryo "bead implantation" assays were utilized to determine whether SDF-1/CXCR4 signaling mediates mesencephalic NCC migration. Results from this study demonstrate that attenuation of SDF-1 signaling, through the use of specific CXCR4 antagonists (AMD3100 and TN14003), disrupts the migration of mesencephalic NCCs into the orofacial region, suggesting a novel role for SDF-1/ CXCR4 signaling in the directed migration of mesencephalic NCCs in the early stage embryo.
\end{abstract}

\section{Keywords}

chemokine; chick embryo; cranial neural crest; CXCR4; orofacial development; SDF-1

\section{INTRODUCTION}

During embryogenesis, neural crest cells (NCCs) migrate into the orofacial region where they form the bones, cartilage and other connective tissues of the face. Surgical removal of avian cranial neural crest (NC) prior to NCC migration results in cleft lip, an abnormally wide palatal cleft (note that avian palates are normally cleft), or a combination of both [1-4]. These observations demonstrate the important role that cranial NCC migration plays in the development of the palate and lip.

(C) 2011 Elsevier Ltd. All rights reserved.

Corresponding Author: Robert M. Greene, Ph.D., Department of Molecular, Cellular and Craniofacial Biology, ULSD, Birth Defects Center, University of Louisville, 501 S. Preston Street, Suite 350, Louisville, KY 40292, Phone: (502) 852-8304; Fax: (502) 852-4702,dr.bob.greene@gmail.com.

Publisher's Disclaimer: This is a PDF file of an unedited manuscript that has been accepted for publication. As a service to our customers we are providing this early version of the manuscript. The manuscript will undergo copyediting, typesetting, and review of the resulting proof before it is published in its final citable form. Please note that during the production process errors may be discovered which could affect the content, and all legal disclaimers that apply to the journal pertain. 
The NC comprises a unique stem cell population that possesses a developmental potential intermediate between that of classically defined mesoderm and ectoderm. NCCs originate from the neural plate (neural ectoderm) (at approximately gestational day 20 in the human; day 8 in the mouse; Hamilton-Hamburger (HH) stage 9 in the chick) along the anteriorposterior axis of the embryo and migrate along characteristic pathways [5-7]. In the cranio/ facial region, these pluripotent cells migrate into the pharyngeal arches forming ectomesenchyme and contribute to tissues such as cartilage, bone, and connective tissue, which - in the trunk- are typically derived from mesoderm. NCCs also give rise to dentinproducing odontoblasts, sensory neurons of cranial ganglia, Schwann cells and meninges (pia and arachnoid mater). In the trunk region, NCCs contribute elements to the peripheral nervous system (both neurons and glia) consisting of sensory ganglia (dorsal root ganglia (DRG)), sympathetic and parasympathetic ganglia and neural plexuses within specific tissues/organs, as well as differentiate into melanocytes of the epidermis [8-10].

The important role played by the NC in craniofacial development has been demonstrated by tissue ablation experiments in chick, and by targeted deletions of genes that affect NC formation in mice [3, 4, 11-17]. Elimination of the $\mathrm{NC}$ from the posterior portion of the avian embryonic prosencephalon and mesencephalon by micro-laser irradiation resulted in the development of homolateral harelip and, in some cases, wide palatal clefts [3].

Mesenchymal insufficiency in the maxillary processes subsequent to $\mathrm{NC}$ ablation has been suggested as causal for cleft lip and palate [4]. The contribution of the NC to mammalian orofacial development is further demonstrated in mouse models by targeted deletion of genes necessary for NCC migration and proliferation $(A p-2 \alpha, M s x 1 / 2$, and $T g f \beta r l / 2)$ that results in orofacial defects [11-15,17].

Chemokines are the central regulators of directed cell migration. The chemokine signaling system consists of over 43 extracellular protein ligands and $18 \mathrm{G}$ protein-coupled receptors which orchestrate leukocyte trafficking and regulate immunity, inflammation, HIV infection and development [18-20]. SDF-1 (Stromal Derived Factor 1, also known as CXCL12) is a secreted protein that is a chemoattractant for T lymphocytes and monocytes in vitro and in vivo [21, 22]. While the first known biological activity of SDF-1 was the stimulation of preB-cell proliferation [23], SDF-1 also affects proliferation and differentiation of various stem cell populations [24-31]. CXCR4 is the receptor for SDF-1 and is believed to be $\mathrm{G}_{\mathrm{i}}$-coupled since signaling is inhibited by pertussis toxin [32].

$S D F-1$ - and $C X C R 4$-deficient mice exhibit defects in the neuronal, vascular, cardiac and hematopoietic systems [33-35]. In $C X C R 4^{-1-}$ and $S D F-1^{-/-}$mice, the cerebellum is disorganized with an attenuated external granule cell layer and with ectopically located Purkinje cells. These mice also display defects in NC-derived cardiac tissue and NC-derived DRG [25]. In gestational day 9.5 wild-type mouse embryos, expression of CXCR4 is observed in NCCs emerging from the dorsal neural tube and in the DRG, while $S D F-1$ is expressed along the path taken by the NCCs to the DRG [25]. More importantly, CXCR4deficient mice exhibit small and malformed DRG demonstrating that SDF-1/CXCR4 signaling is necessary for NCC migration to sites of DRG formation [25]. No functional redundancy has been found for the SDF-1 and CXCR4 proteins as deletion or inactivation of either of the cognate genes is lethal; and, the phenotypes of SDF-1-deficient and of CXCR4deficient mice are identical $[33,35]$.

Chick SDF-1 is $90 \%$ identical to the mature mouse protein and contains identical conserved motifs [36, 37]. The active human, mouse and chick isoform of SDF-1 contains 89 amino acid residues of which the first $\sim 20$ residues constitute the secretion signal peptide [37]. CXCR4 is a seven-transmembrane domain protein comprising 352 amino acid residues in human, and 359 in mouse and chick. Chick SDF-1 was recently cloned and its temporal and 
spatial expression patterns have been examined [36, 37, 38]. SDF-1 encodes two proteins of 89 and 131 amino acids, but only the former (the active SDF-1 protein in other species) has biological activity [37]. $S D F-1$ is expressed ubiquitously and constitutively in adult tissues and is present as early as the primitive streak of chick embryos [37]. Complementarity in $S D F-1$ and $C X C R 4$ expression patterns is evident at various stages in chick embryonic development and is especially dramatic along the anterior-posterior axis [38-40]. While $S D F-1$ expression can be detected as early as the epiblast stage, CXCR4 expression at this stage is mostly confined to the developing mesoderm and endoderm; after establishment of the germ layers (at $\mathrm{HH} 14-16$ ), $S D F-1$ expression is observed in the overlying ectoderm while $C X C R 4$ expression is found in the underlying mesoderm as it differentiates into the paraxial, intermediate and lateral plate mesoderm [40]. With somitogenesis, a progressive decline in $S D F-1$ expression is observed towards the cranial region in the ectoderm, and by HH18 SDF- 1 expression ceases altogether in the ectoderm and the ectoderm-derived neural tube, at which stage the neural tube is positive for CXCR4 expression [38, 40].

CXCR4 mediates the migration of numerous cell types including NCCs towards sources of SDF-1 [24-26, 29, 34, 37, 41]. SDF-1/CXCR4 signaling plays a crucial role in neuronal migration and axonal pathfinding where SDF-1 mediates the emergence of developing motor axons from the spinal cord as well as stimulates axonal branching [28, 42]. SDF-1 mediates the migration of non neural cells as well, mainly in response to ischemic tissue injury [27, 30]. Recent work has shown that SDF-1/CXCR4 signaling provides directional cues to primordial germ cells during their migration to the developing gonad in mouse, zebrafish and chick [24, 26, 29, 37, 41]. A more recent study indicates that a subpopulation of trunk NCCs expressing CXCR4 preferentially migrate to form the neural core of the sympathetic ganglia, further emphasizing the importance of the SDF-1/CXCR4 signaling axis in NCC migration and NCC-derived tissue differentiation [43].

In view of the central role that SDF-1/CXCR4 signaling plays in the differentiation and migration of different stem cell lineages, we hypothesized that this chemokine signaling system also may play an important role in regulating mesencephalic (cranial) NCC migration into the orofacial region.

\section{MATERIALS AND METHODS}

Eggs from white Leghorn chickens were purchased from Charles River Laboratories (Wilmington, MA) and stored humidified at $12^{\circ} \mathrm{C}$ until use. Embryos were staged according to the Hamilton Hamburger $(\mathrm{HH})$ method $[44,45]$. Chick eggs were incubated at $39^{\circ} \mathrm{C}$ for 32-36 hours, during which time embryos developed to HH 9-10 (8-12 somites). Both the SDF-1 ligand (R\&D Systems, Minneapolis, MN) and the specific inhibitor of the CXCR4 receptor, AMD3100 (1,1'-[1,4-phenylyenebis (methylene)] bis-[1,4,8,11-tetraazacyclotetradecane] octahydrochloride; Sigma, St. Louis, MO) were obtained commercially. For in vivo assays, SDF-1/CXCR4-mediated signaling and migration were inhibited by a CXCR4 antagonist, an amidylated 14 residue peptide, TN14003 (Invitrogen Custom Peptide Services, Carlsbad, CA; GenScript, Piscataway, NJ) [46].

\subsection{Transwell cell migration assays}

Chick embryos at HH 10-11 were dissected from the yolk and transferred to calcium/ magnesium-free phosphate buffered saline (PBS) using published methods [47]. To isolate embryonic tissue containing migrating NCCs, the vitelline membrane was first pulled away from the rostral region. Tungsten dissecting needles were then used to cut posterior to the optic vesicles, then anterior to the presumptive left ventricle, and finally down the mid-line of the mesencephalic neural tube (Fig. 1). The two lateral flaps of tissue thus formed were subsequently separated and the region from the dorsal most edges (corresponding to the 
neural crest) was microdissected away from the rest of the ventral tissue (Fig. 1B). Microdissected neural crest tissue from 6 embryos was pooled for each transwell experiment. Cells were dissociated by tryptic digestion and resuspended in DMEM-F12 (Gibco-Invitrogen, NY)/10\% fetal bovine serum (Atlanta Biologicals, GA) at a concentration of $3 \times 10^{4}$ cells $/ 100 \mu$ l. Cells were seeded into the upper chambers of $6.5 \mathrm{~mm}$ diameter $8.0 \mu \mathrm{m}$ pore FluoroBlok ${ }^{\mathrm{TM}}$ polyethylene terephthalate transwell culture plate (BD Falcon, BD Biosciences, Franklin Lakes, NJ). The use of transwells with a fluorescent block allowed the quantification of fluorescent cells on both sides of the membrane without fluorescent bleed-through. Transwell cell migration experiments were designed in three configurations: [1] vehicle in the lower chamber; [2] SDF-1 (100 ng/ml) in the lower chamber; and [3] AMD3100 $(40 \mu \mathrm{M})$ [a specific inhibitor of SDF-1/CXCR4 signaling] in the upper chamber and SDF-1 (100 ng/ml) in the lower chamber. Each experiment was performed in triplicate and the study replicated with four biologically independent cell samples. Transwell cultures were incubated overnight in a humidified tissue culture incubator at $37^{\circ} \mathrm{C}$ with $5 \% \mathrm{CO}_{2}$. Subsequently, membranes from the transwell cultures were processed for immunolocalization of NCCs by incubating with anti-HNK-1 antibody (1 $\mu \mathrm{g} /$ $\mathrm{ml}$; mouse IgM anti-CD57; Zymed Laboratories, San Francisco, CA) overnight at $4^{\circ} \mathrm{C}$ followed by anti-mouse IgM Alexa Fluor (AF)-488 antibody ( $10 \mu \mathrm{g} / \mathrm{ml}$; Invitrogen) for $1 \mathrm{~h}$ at $37^{\circ} \mathrm{C}$. Cells were counterstained with DAPI (DAPI-dilactose; Sigma) prior to being mounted on slides under Fluoromount-G (Cell Lab; Beckman Coulter, Fullerton, CA). Cells that were positive for both HNK-1 and DAPI fluorescence were counted on both sides of each membrane to determine the percentage of migrated NCCs. The migration index (MI) was calculated as follows: [number of migrated cells (cells in the lower well)/total number of cells (cells in the upper + lower wells) $] \times 100$. The number of non-NCCs was determined by subtracting HNK-1 positive NCCs from the total number of cells (DAPI stained).

\subsection{Inhibition of cell migration in vivo}

Chick agar culture medium consisting of 50\% thin albumin (from unincubated eggs), 62 $\mathrm{mM} \mathrm{NaCl}, 0.3 \%$ BactoAgar, penicillin (75 units $/ \mathrm{ml})$ - streptomycin $(75 \mu \mathrm{g} / \mathrm{ml})$ was prepared as previously described [48]. Agarose beads (Affi-Gel, 100-200 mesh, Bio-Rad, Hercules, CA) were washed 3 times with PBS, then soaked in either the CXCR4 antagonist TN14003 $(10 \mathrm{mg} / \mathrm{ml})$ or BSA $(10 \mathrm{mg} / \mathrm{ml})$ overnight at $4{ }^{\circ} \mathrm{C}$. HH 9-10 chick embryos were dissected and transferred onto $35 \mathrm{~mm}$ Petri dishes containing chick agar culture medium. Dissecting needles were used to make a small slit into the dorsal neural tube, posterior to the axis of the optic vesicles, into which $\sim 6$ beads, soaked with either TN14003, or BSA, were inserted. Embryos were then incubated for $18 \mathrm{~h}$ at $37-38^{\circ} \mathrm{C}$ inside a humidified chamber. After incubation, embryos were photographed using a Nikon SMZ1500 stereomicroscope equipped with a Nikon DXM 1200 camera and ACT-1 software. Embryos were then dissected away from the surrounding vitelline membrane, fixed in $4 \%$ paraformaldehyde in PBS and processed for cryopreservation in $30 \%$ sucrose/PBS for at least $30 \mathrm{~min}$, then in $15 \%$ sucrose in OCT (optimal cutting temperature compound; Tissue-Tek 4583, Sakura Finetek USA, Inc., Torrance, CA) for 30 min before embedding in OCT for freezing. Transverse serial sections were cut at a thickness of $10 \mu \mathrm{m}$, dried overnight at room temperature and processed for immunolocalization of NCCs using anti-HNK-1 antibody as described previously for transwell membranes.

HNK-1-positive fluorescence in sections was examined using a Nikon TE-2000-U microscope with a Xenon Arc lamp and equipped with CoolSnap ES digital camera and MetaMorph software (Universal Imaging Inc., Downingtown, PA). NCC emergence was quantified by measuring the total area of HNK-1 fluorescence in 6 sections from each embryo as a percentage of DAPI fluorescence from the same 6 sections. Threshold parameters were set prior to measurements based upon HNK-1 fluorescence intensity in 
sections from BSA-treated embryos. The effect of inhibition was computed by calculating the ratio of the percentage of NCCs in TN14003-treated embryos to those in BSA-treated embryos. Results were derived from four biologically independent experiments.

\subsection{Cell proliferation and apoptosis assays}

Cell proliferation was measured by BrdU incorporation. BrdU solution $(10 \mu \mathrm{M}$; Molecular Probes) was added through the slit (used for bead implantation) in the chorioallantoic membrane and the cultures were maintained at $38^{\circ} \mathrm{C}$ for $18 \mathrm{~h}$ in a humidified chamber. The embryos were then processed for cryopreservation as described above. For BrdU detection, $8 \mu \mathrm{m}$ sections were post-fixed with $70 \%$ ethanol for $20 \mathrm{~min}$ and washed with PBS. DNA was denatured with $2 \mathrm{~N} \mathrm{HCl}$ for $20 \mathrm{~min}$ at $37^{\circ} \mathrm{C}$ and subsequently neutralized using Boric buffer $(0.05 \mathrm{M}, \mathrm{pH} 8.5)$ for $10 \mathrm{~min}$ at $37^{\circ} \mathrm{C}$. Sections were washed in PBS and permeabilized in PBS containing 0.3\% Triton X-100. Nonspecific staining was blocked using PBS $/ 0.1 \%$ Triton $\mathrm{X}-100 / 1 \% \mathrm{BSA} / 5 \% \mathrm{FBS}$ for $30 \mathrm{~min}$ at $37^{\circ} \mathrm{C}$. The sections were exposed to anti-HNK-1 antibody overnight at $4^{\circ} \mathrm{C}$, and then washed in PBS. BrdU staining was performed using AF-594 labeled anti-BrdU (Molecular Probes/Invitrogen, Carlsbad, $\mathrm{CA}$ ) at $1 / 25$ dilution in blocking buffer for $1 \mathrm{~h}$ at $37^{\circ} \mathrm{C}$ in combination with AF-488 labeled anti-IgM (Molecular Probes/Invitrogen) to detect HNK-1. After washing in PBS, nuclei were counterstained with DAPI for 5 min and mounted with Fluoromount-G.

Apoptosis was measured using a TUNEL (terminal deoxynucleotidyl transferase [TdT] dUTP nick labeling) assay (Roche, Indianapolis, IN). Chick embryo sections were processed according to the manufacturer's instructions, and incubated overnight at $4^{\circ} \mathrm{C}$ with antiHNK-1 antibody. The next day, TUNEL mix was added to the sections in combination with AF-488 labeled anti-IgM to detect HNK-1 and incubated for $1 \mathrm{~h}$ at $37^{\circ} \mathrm{C}$. Sections were counterstained with DAPI and mounted as described above.

\subsection{Whole embryo in situ hybridization}

Coding regions for chick SDF-1 (425 bp) and CXCR4 (689 bp) were obtained by PCR amplification of cDNAs prepared from chick embryo total RNA, and cloned into pGEM-T Easy vectors (Promega). Each vector was linearized by digestion with SalI (for generating the antisense probe by transcription with T7 RNA polymerase) or XhoI (for generating the sense probe by transcription with SP6 RNA polymerase). Riboprobes were prepared using the DIG Labeling System (Roche). Chick embryos, transferred to Whatman filter paper discs having a small aperture, were processed in PBS, fixed with 4\% paraformaldehyde overnight, gradually dehydrated with increasing concentrations of methanol and stored at $-20^{\circ} \mathrm{C}$ until required. Embryos were used for in situ hybridization as described [49].

\subsection{Statistical analyses}

Statistical significance was analyzed by unpaired, two-tailed Student's $t$-test using GraphPad software (GraphPad Software, Inc., La Jolla, CA). Values are expressed as mean \pm Standard Deviation. For the transwell cell migration assays (Fig. 3), the mean is the average of four experiments, each conducted in triplicate. For the in vivo bead implantation assays (Fig. 6), the mean is from measurements of four different embryos cultured under the stated conditions, each the average of results from six different sections. Values of $\mathrm{p}<0.05$ were considered statistically significant.

\section{RESULTS}

\subsection{SDF-1 promotes mesencephalic NCC migration in vitro}

In order to verify the spatio-temporal expression of SDF-1 and its receptor, CXCR4, in the mesencephalic region of chick embryos at the onset of NCC migration at HH 9-10, in situ 
hybridization on whole embryos was performed using riboprobes for chick $S D F-1$ and CXCR4. CXCR4 was found to be expressed in the mesencephalic neural tube, around the optic vesicle and in the cardiac septum. Diffuse streams of CXCR4-expressing cells, in identical regions of NCC migration toward the ventral regions of the embryo, were apparent (Fig. 2A). No $S D F-1$ expression was observed in the forming neural tube at this stage, but a high level of $S D F-1 \mathrm{mRNA}$ expression was seen in the brain region around the optic vesicles (Fig. 2B). The inset in Fig. 2B shows a ventral view of the same embryo with $S D F-1$ expression in lateral aspects of the embryo. These observations indicate that CXCR4 is strongly expressed in the dorsal aspect of the developing neural tube and in an apparent population of cells migrating from the forming neural tube in $\mathrm{HH} 9-10$ chicks, while a more diffuse expression of its ligand, $S D F-1$, is seen in the craniofacial area.

The role of SDF-1/CXCR4 in the migration of NCCs derived from the mesencephalic region of HH 10-11 chick embryos was quantified using transwell assays. NCCs were seeded into the upper chamber of each transwell and subjected to analysis under the following 3 conditions: (1) vehicle alone in the lower chamber; (2) SDF-1 alone in the lower chamber; and (3) SDF-1 in the lower chamber with the CXCR4 antagonist, AMD3100, in the upper chamber, as detailed in Section 2.1. The migration index (MI) was calculated as the ratio of the percentage of migrated cells to the total number of migrated and unmigrated cells using HNK-1 immunofluorescence as a positive marker for NCCs. As seen in Fig. 3A, SDF-1 promoted a chemotactic response in the NCCs with a MI typically 1.8 fold higher $(\mathrm{p}<0.03)$ than that seen with vehicle alone (MI: $34.5 \pm 8.4$ vs. $19.7 \pm 5.4$ ). AMD3100, a CXCR4 antagonist and specific inhibitor of SDF-1 signaling, was able to abrogate the SDF-1 mediated increase in MI to near-control levels (MI: $20.9 \pm 8.5$ vs. $19.7 \pm 5.4$ ). The mean migration index, noted in Fig. 3A, is the average from four experiments, each conducted in triplicate. Results from a single representative experiment are shown in the inset of Fig. 3A. These results indicate that chick embryo mesencephalic NCCs migrate in response to SDF-1/CXCR4 signaling in vitro.

\subsection{SDF-1-induced chemotaxis is restricted to NCCs in the mesencephalic cell population}

In order to determine whether SDF-1-induced chemotaxis was a general property of mesencephalic cells (i.e. neural crest and non-neural crest cells derived from the mesencephalic region of the embryo), the transwell culture study described in Section 3.1 was repeated and DAPI staining was used to determine the total number of migratory and non-migratory cells. DAPI binds to DNA and stains the nuclei of all cells. While the MI of the total population of migrating cells (DAPI stained) was similar between all conditions (data not shown), the MI calculated for the non-NCC population was actually lower, though not statistically significant, when treated with SDF-1 (MI: $18.3 \pm 6.3$ vs. $15.4 \pm 9.1$; Fig. 3B). AMD3100 had no significant effect on the migration of these cells (MI: $15.9 \pm 8.6$ vs. $15.4 \pm 9.1$ ). These results, therefore, suggest a specific chemoattractant effect of SDF-1 on the cranial NCC population of chick embryo mesencephalic cells in vitro - an observation that was further investigated in vivo (ex ovo), as detailed below.

\subsection{Inhibition of endogenous SDF-1 signaling disrupts mesencephalic NCC migration in vivo (ex ovo)}

Chick whole embryo culture was used to investigate the effect of inhibiting endogenous SDF-1/CXCR4 signaling on mesencephalic NCC migration. Inhibition of SDF-1/CXCR4 signaling was achieved by implanting agarose beads soaked with TN14003, a CXCR4 peptidic antagonist, in the embryo. Beads soaked with either TN14003 or BSA were implanted into the dorsal mesencephalic neural tube during the initiation of NCC migration on HH 9-10. Fig. 4A shows an HH 9-10 embryo with BSA-soaked beads implanted into the developing cranial neural tube. Following implantation of the BSA-soaked beads and 
overnight incubation at $37^{\circ} \mathrm{C}$, embryos developed to stage $\mathrm{HH} 13-14$, exhibiting marked growth, an expanded cardiac ventricle, and vascularization of the vitelline membrane - all indicative of embryonic viability (Fig. 4B). The effects of inhibiting SDF-1/CXCR4 signaling on embryonic NCC migration were assessed in tissue sections immunostained with HNK-1 antibody. Implantation of beads soaked with TN14003 into the dorsal mesencephalic neural tube inhibited NCC migration, as evidenced by a failure of ventral migration of the NCC population in the embryo with a resultant localization of the majority of NCCs in the vicinity of the implanted beads and in the lumen of the neural tube (Fig. 5E/ $\mathrm{H}, 7 \mathrm{E}$ and $8 \mathrm{E}$ ). Evaluation of the number of HNK-1-fluorescent NCCs normalized to DAPIfluorescent total cells, measured in equivalent sections, revealed an $86 \%$ reduction $(\mathrm{p}<0.03)$ in the number of migrated NCCs in TN14003-treated embryos compared to the number of migrated cells in BSA-treated embryos (Fig. 6), suggesting that endogenous SDF-1/CXCR4 signaling is requisite for embryonic mesencephalic NCC migration.

\subsection{Inhibition of endogenous SDF-1 signaling in chick embryos in vivo reduces cell proliferation in the mesencephalic neural tube}

To further evaluate the effect of inhibition of SDF-1/CXCR4 signaling by TN14003 on NCC migration in vivo, cryosections, from the mesencephalic region of the embryos which were implanted with either BSA- or TN14003-soaked beads and incubated overnight, were evaluated for apoptosis and cell proliferation. A TUNEL assay was utilized for apoptosis assessment, in combination with HNK-1 labeling for NCC (Fig. 7). Although a slight increase in overall apoptosis in embryos was noted in the agar culture model used for these experiments, there was no significant difference in the level of apoptosis in embryos implanted with TN14003-soaked beads (Fig. 7D-F) compared to the level of apoptosis in embryos implanted with BSA-soaked beads (Fig. 7A-C). As previously noted (Fig. 5), a significant proportion of NCCs in TN14003-treated embryos appeared to have aberrantly migrated into the lumen of the neural tube (arrowheads in Fig. 7E), compared to BSAtreated embryos in which NCCs were found predominantly outside - and migrating away from - the neural tube (arrowheads Fig. 7B).

Evaluation of the effect of inhibition of SDF-1/CXCR4 signaling by TN14003 on NCC cell proliferation (Fig. 8) revealed differences in BrdU incorporation between BSA and TN14003- treated embryos. As noted previously, altered NCC migratory patterns were observed when SDF-1/CXCR4 signaling was inhibited by TN14003. The level of proliferation in the neuroepithelium of the developing neural tube was reduced following treatment with TN14003 (Fig. 8D) when compared to levels following treatment with the vehicle, BSA (Fig. 8A). The population of NCCs that aberrantly migrated to the lumen of the neural tube following SDF1-CXCR4 inhibition (Fig. 8E) was found to be actively proliferating (Fig. 8F, arrows); however, no evidence of proliferation was observed in NCCs that have migrated out of the neural tube (Fig. 8F). These data suggest that abrogation of SDF-1/CXCR4 signaling in mesencephalic region of the developing embryo does not affect proliferation or apoptosis of NCCs in the neural tube but alters the migratory potential of NCCs.

\section{DISCUSSION}

In the current study, results from transwell cell migration assays using embryonic mesencephalic NCCs and bead implantation studies in chick whole embryo culture clearly demonstrated that SDF-1 is a chemoattractant for mesencephalic NCCs both in vitro and in vivo. These results are similar to the chemotactic response exhibited by murine trunk NCCs towards SDF-1 in vitro [25,33-35]. In chick whole embryo culture, the CXCR4-inhibitory binding peptide, TN14003, impaired the migration of NCCs into the ventral region of the embryo, suggesting that SDF-1 is involved in the directed migration of mesencephalic NCCs 
in vivo. This inhibition of NCC migration can be attributed to the inability of endogenous SDF-1 to bind NCC CXCR4 receptors since the receptor binding site was occupied by the inhibitory peptide, TN14003.

Previous studies have demonstrated expression of CXCR4, the SDF-1 receptor, in migrating NCCs in vivo, and that SDF-1 elicits a chemotactic response from NCCs in vitro. Migration of trunk NCCs into the DRG was found to be defective in CXCR4-deficient mice, but defects in cranial (mesencephalic) NCC migration were not reported [25,33-35]. The lack of an observed cranial phenotype in CXCR4-deficient mice may be attributed to a functional redundancy with FGF2, the major chemotactic factor for NC migration. Indeed, FGF-2deficient mice exhibit a marked NC-related phenotype [48, 50-51]. The difference observed in phenotypes between CXCR4-deficient mice and avian embryos in which SDF1/CXCR4 signaling is blocked, as in the present study, may be due to differences in expression of FGF2 between the two species at the time of NCC migration. Moreover, SDF-1- or CXCR4deficient embryos developing in utero have been examined for gross morphological defects, not for defects in NCC migration at the cellular level. The presence of transcripts for SDF-1 and CXCR4 in the mesencephalic region of the embryo at the onset of NCC migration poises these molecules for a role in cell migration. One limitation of the ex-ovo chick embryo culture system used in the current study is that embryos beyond the 30-somite stage do not develop well and have reduced viability, thus precluding examination of their gross morphology. Therefore, it is possible that the defects in cranial NCC migration in chick embryo culture that we report do not translate into gross orofacial dysmorphology during later embryonic development.

It is unlikely that the observed effects of the CXCR4 antagonist, TN14003, in vivo are due to inhibition of pathways other than SDF-1/CXCR4 signaling. The peptide inhibitor TN14003 occupies a site on the CXCR4 receptor that is normally bound by SDF-1, an interaction that is highly specific. CXCR7 also binds SDF-1, and until recently, such interaction was thought to result in ligand sequestration, not signal transduction [52-54]. Recent studies on transendothelial migration, however, indicate that CXCR7 may be associated with intracellular signaling [55]. Specifically, it has been found that CXCR7 can regulate SDF-1/CXCR4 mediated transendothelial migration. This presumably occurs through $\beta$-arrestin2, an intracellular signaling molecule that can cross-talk with CXCR4 and CXCR7. SDF-1 can trigger $\beta$-arrestin2 association with both CXCR4 and CXCR7 receptors $[55,56]$. Sequestration of $\beta$-arrestin 2 by CXCR 7 will curtail $\beta$-arrestin 2 signaling permitting enhanced signaling via CXCR4 [55]. Nevertheless, the profound inhibition (86\%) of mesencephalic NCC migration observed with TN14003 in our study (Fig. 6) rules out a major role for CXCR7 in cranial NCC migration. The precise molecular mechanisms underlying the directional migration of cells expressing CXCR4 towards the chemoattractant, SDF-1 is complex and not well understood [57]. It involves signaling cascades that control F-actin formation and remodeling of the actin cytoskeleton [57, 58], and N-cadherin mediated contact inhibition of locomotion [59]. Migration may also be facilitated by inhibitory cues lining the migratory route [59].

In addition to regulating directed cell migration, SDF-1/CXCR4 signaling is also known to play a major role in cell survival, proliferation and maturation [60, 61]. Survival of dendritic cells [60], and hematopoietic stem and progenitor cells [60] has been shown to depend on SDF-1/CXCR4 signaling. Thus the absence of SDF1 migratory cues may trigger signals that not only curtail the migration of CXCR4 bearing mesencephalic NCCs, but also their formation and or survival. While there was no difference in cell apoptosis in the mesencephalic neural tube in embryos exposed to TN14003, migration of NCCs was markedly affected. NCCs, which normally migrate out of the neural tube toward their target cues, were, instead, found lining the lumen side of the neural tube in close proximity to the 
TN14003-soaked beads (and some even around the beads), presumably by traversing through the neural tube. These NCCs were proliferative in nature (i.e., BrdU positive), thus indicating that cell proliferation per se was not affected by TN14003. A small number of NCCs, however, was observed to have migrated out of the neural tube in the presence of TN14003 (Fig. 5, 7E and 8E). Whether these cells have traversed the mesenchyme in specific spatial pathways without encountering the CXCR4 inhibitor, or whether they represent a sub-population of cranial NCCs that are independent of SDF-1/CXCR4 signaling remains to be determined. Thus, perturbations in SDF-1/CXCR4 signaling in the mesencephalic neural tube appear to impede the migration of NCCs, thereby resulting in depletion of NCCs that migrate out of the neuroepithelium. Neural stem and progenitor cells have been shown to express CXCR4 and therefore respond to SDF-1 chemoattraction [62, 63]. Precursors for the peripheral sensory system originate from NCCs, and therefore, the neuronal precursors arising from the cranial region could be more sensitive to perturbations in SDF-1/CXCR4 signaling, as shown previously for trunk NCCs [25]. Interestingly, a recent study has demonstrated that VEGF signaling through neuropilin-1 can mediate the migration of chick cranial NCC into the second branchial arch [64]. Regardless of the mechanism by which directed NCC migration to specific target sites in the developing orofacial region is regulated and/or perturbed, the presence of insufficient NCCs in target tissues can be expected to contribute to abnormal orofacial development. Collectively, results from the present study support a key role for the SDF-1/CXCR4 signaling system in directing embryonic mesencephalic NCC migration into the presumptive orofacial area and suggest that aberrant SDF-1/CXCR4 signaling can contribute to orofacial defects.

\section{Acknowledgments}

This work was supported in part by a grant from the Cleft Palate Foundation, NIH grants DE018215, HD053509, and NIH P20 RR017702 from the COBRE program of the National Center for Research Resources.

\section{References}

1. Been W, Lieuw Kie Song SH. Harelip and cleft palate conditions in chick embryos following local destruction of the cephalic neural crest. A preliminary note. Acta Morphol Neerl Scand. 1978; 16:245-55. [PubMed: 742411]

2. Been W, Lieuw Kie Song SH, van Limborgh J. Developmental anomalies of the lower face and the hyoid cartilage due to partial elimination of the posterior mesencephalic and anterior rhombencephalic neural crest in chick embryos. Acta Morphol Neerl Scand. 1984; 22:265-78. [PubMed: 6524460]

3. Lieuw Kie Song SH, Been W. Median facio-cerebral anomalies in chick embryos resulting from local destruction of the anteriormost parts of the early neural plate and neural crest. Acta Morphol Neerl Scand. 1980; 18:231-52. [PubMed: 7415879]

4. van Limborgh J, Lieuw Kie Song SH, Been W. Cleft lip and palate due to deficiency of mesencephalic neural crest cells. Cleft Palate J. 1983; 20:251-9. [PubMed: 6577988]

5. Kontges G, Lumsden A. Rhombencephalic neural crest segmentation is preserved throughout craniofacial ontogeny. Development. 1996; 122:3229-42. [PubMed: 8898235]

6. Lumsden A, Sprawson N, Graham A. Segmental origin and migration of neural crest cells in the hindbrain region of the chick embryo. Development. 1991; 113:1281-91. [PubMed: 1811942]

7. Serbedzija GN, Bronner-Fraser M, Fraser SE. Vital dye analysis of cranial neural crest cell migration in the mouse embryo. Development. 1992; 116:297-307. [PubMed: 1283734]

8. Hall, BK.; Horstadius, S. The neural crest. London: Oxford University Press; 1988.

9. Hall, BK. The Neural Crest in Development and Evolution. New York: Springer; 1999.

10. Le Douarin, NM.; Kalcheim, C. The Neural Crest. 2. Cambridge: Cambridge University Press; 1999. 
11. Brewer S, Feng W, Huang J, Sullivan S, Williams T. Wnt1-Cre-mediated deletion of AP-2 alpha causes multiple neural crest-related defects. Dev Biol. 2004; 267:135-52. [PubMed: 14975722]

12. Dixon J, Jones NC, Sandell LL, Jayasinghe SM, Crane J, Rey JP, et al. Tcof1/Treacle is required for neural crest cell formation and proliferation deficiencies that cause craniofacial abnormalities. Proc Natl Acad Sci U S A. 2006; 103:13403-8. [PubMed: 16938878]

13. Dudas M, Kim J, Li WY, Nagy A, Larsson J, Karlsson S, et al. Epithelial and ectomesenchymal role of the type I TGF-beta receptor ALK5 during facial morphogenesis and palatal fusion. Dev Biol. 2006; 296:298-314. [PubMed: 16806156]

14. Ishii M, Han J, Yen HY, Sucov HM, Chai Y, Maxson RE Jr. Combined deficiencies of Msx1 and Msx 2 cause impaired patterning and survival of the cranial neural crest. Development. 2005; 132:4937-50. [PubMed: 16221730]

15. Ito Y, Yeo JY, Chytil A, Han J, Bringas P Jr, Nakajima A, et al. Conditional inactivation of Tgfbr2 in cranial neural crest causes cleft palate and calvaria defects. Development. 2003; 130:5269-80. [PubMed: 12975342]

16. Johnston MC. The neural crest in abnormalities of the face and brain. Birth Defects Orig Artic Ser. 1975; 11:1-18. [PubMed: 813792]

17. Xu X, Bringas P Jr, Soriano P, Chai Y. PDGFR-alpha signaling is critical for tooth cusp and palate morphogenesis. Dev Dyn. 2005; 232:75-84. [PubMed: 15543606]

18. Kim CH, Broxmeyer HE. Chemokines: signal lamps for trafficking of T and B cells for development and effector function. J Leukoc Biol. 1999; 65:6-15. [PubMed: 9886241]

19. McGrath KE, Koniski AD, Maltby KM, McGann JK, Palis J. Embryonic expression and function of the chemokine SDF-1 and its receptor, CXCR4. Dev Biol. 1999; 213:442-56. [PubMed: 10479460]

20. Simmons G, Reeves JD, McKnight A, Dejucq N, Hibbitts S, Power CA, et al. CXCR4 as a functional coreceptor for human immunodeficiency virus type 1 infection of primary macrophages. J Virol. 1998; 72:8453-7. [PubMed: 9733901]

21. Aiuti A, Webb IJ, Bleul C, Springer T, Gutierrez-Ramos JC. The chemokine SDF-1 is a chemoattractant for human CD34+ hematopoietic progenitor cells and provides a new mechanism to explain the mobilization of CD34+ progenitors to peripheral blood. J Exp Med. 1997; 185:11120. [PubMed: 8996247]

22. Bleul CC, Fuhlbrigge RC, Casasnovas JM, Aiuti A, Springer TA. A highly efficacious lymphocyte chemoattractant, stromal cell-derived factor 1 (SDF-1). J Exp Med. 1996; 184:1101-9. [PubMed: 9064327]

23. Nagasawa T, Kikutani H, Kishimoto T. Molecular cloning and structure of a pre-B-cell growthstimulating factor. Proc Natl Acad Sci U S A. 1994; 91:2305-9. [PubMed: 8134392]

24. Ara T, Nakamura Y, Egawa T, Sugiyama T, Abe K, Kishimoto T, et al. Impaired colonization of the gonads by primordial germ cells in mice lacking a chemokine, stromal cell-derived factor-1 (SDF-1). Proc Natl Acad Sci U S A. 2003; 100:5319-23. [PubMed: 12684531]

25. Belmadani A, Tran PB, Ren D, Assimacopoulos S, Grove EA, Miller RJ. The chemokine stromal cell-derived factor-1 regulates the migration of sensory neuron progenitors. J Neurosci. 2005; 25:3995-4003. [PubMed: 15843601]

26. Doitsidou M, Reichman-Fried M, Stebler J, Koprunner M, Dorries J, Meyer D, et al. Guidance of primordial germ cell migration by the chemokine SDF-1. Cell. 2002; 111:647-59. [PubMed: 12464177]

27. Gomperts BN, Belperio JA, Rao PN, Randell SH, Fishbein MC, Burdick MD, et al. Circulating progenitor epithelial cells traffic via CXCR4/CXCL12 in response to airway injury. J Immunol. 2006; 176:1916-27. [PubMed: 16424223]

28. Lieberam I, Agalliu D, Nagasawa T, Ericson J, Jessell TM. A Cxcl12-Cxcr4 chemokine signaling pathway defines the initial trajectory of mammalian motor axons. Neuron. 2005; 47:667-79. [PubMed: 16129397]

29. Molyneaux KA, Zinszner H, Kunwar PS, Schaible K, Stebler J, Sunshine MJ, et al. The chemokine SDF1/CXCL12 and its receptor CXCR4 regulate mouse germ cell migration and survival. Development. 2003; 130:4279-86. [PubMed: 12900445] 
30. Togel F, Isaac J, Hu Z, Weiss K, Westenfelder C. Renal SDF-1 signals mobilization and homing of CXCR4-positive cells to the kidney after ischemic injury. Kidney Int. 2005; 67:1772-84. [PubMed: 15840024]

31. Vasyutina E, Stebler J, Brand-Saberi B, Schulz S, Raz E, Birchmeier C. CXCR4 and Gab1 cooperate to control the development of migrating muscle progenitor cells. Genes Dev. 2005; 19:2187-98. [PubMed: 16166380]

32. Moepps B, Frodl R, Rodewald HR, Baggiolini M, Gierschik P. Two murine homologues of the human chemokine receptor CXCR4 mediating stromal cell-derived factor 1 alpha activation of Gi2 are differentially expressed in vivo. Eur J Immunol. 1997; 27:2102-12. [PubMed: 9295051]

33. Ma Q, Jones D, Borghesani PR, Segal RA, Nagasawa T, Kishimoto T, et al. Impaired Blymphopoiesis, myelopoiesis, and derailed cerebellar neuron migration in CXCR4- and SDF-1deficient mice. Proc Natl Acad Sci U S A. 1998; 95:9448-53. [PubMed: 9689100]

34. Nagasawa T, Hirota S, Tachibana K, Takakura N, Nishikawa S, Kitamura Y, et al. Defects of Bcell lymphopoiesis and bone-marrow myelopoiesis in mice lacking the CXC chemokine PBSF/ SDF-1. Nature. 1996; 382:635-8. [PubMed: 8757135]

35. Zou YR, Kottmann AH, Kuroda M, Taniuchi I, Littman DR. Function of the chemokine receptor CXCR4 in haematopoiesis and in cerebellar development. Nature. 1998; 393:595-9. [PubMed: 9634238]

36. Read LR, Cumberbatch JA, Buhr MM, Bendall AJ, Sharif S. Cloning and characterization of chicken stromal cell derived factor-1. Dev Comp Immunol. 2005; 29:143-52. [PubMed: 15450754]

37. Stebler J, Spieler D, Slanchev K, Molyneaux KA, Richter U, Cojocaru V, et al. Primordial germ cell migration in the chick and mouse embryo: the role of the chemokine SDF-1/CXCL12. Dev Biol. 2004; 272:351-61. [PubMed: 15282153]

38. Rehimi R, Khalida N, Yusuf F, Dai F, Morosan-Puopolo G, Brand-Saberi B. Stromal-derived factor-1 (SDF-1) expression during early chick development. Int J Dev Biol. 2008; 52:87-92. [PubMed: 18033676]

39. Liang TS, Hartt JK, Lu S, Martins-Green M, Gao JL, Murphy PM. Cloning, mRNA distribution, and functional expression of an avian counterpart of the chemokine receptor/HIV coreceptor CXCR4. J Leukoc Biol. 2001; 69:297-305. [PubMed: 11272281]

40. Yusuf F, Rehimi R, Dai F, Brand-Saberi B. Expression of chemokine receptor CXCR4 during chick embryo development. Anat Embryol (Berl). 2005; 210:35-41. [PubMed: 16047188]

41. Knaut H, Werz C, Geisler R, Nusslein-Volhard C. A zebrafish homologue of the chemokine receptor Cxcr4 is a germ-cell guidance receptor. Nature. 2003; 421:279-82. [PubMed: 12508118]

42. Pujol F, Kitabgi P, Boudin H. The chemokine SDF-1 differentially regulates axonal elongation and branching in hippocampal neurons. J Cell Sci. 2005; 118:1071-80. [PubMed: 15731012]

43. Kasemeier-Kulesa JC, McLennan R, Romine MH, Kulesa PM, Lefcort F. CXCR4 controls ventral migration of sympathetic precursor cells. J Neurosci. 2010; 30:13078-88. [PubMed: 20881125]

44. Hamburger V. The stage series of the chick embryo. Dev Dyn. 1992; 195:273-5. [PubMed: 1304822]

45. Hamburger V, Hamilton HL. A series of normal stages in the development of the chick embryo. Dev Dyn. 1992; 195:231-72. [PubMed: 1304821]

46. Tamamura H, Omagari A, Hiramatsu K, Gotoh K, Kanamoto T, Xu Y, et al. Development of specific CXCR4 inhibitors possessing high selectivity indexes as well as complete stability in serum based on an anti-HIV peptide T140. Bioorg Med Chem Lett. 2001; 11:1897-902. [PubMed: 11459656]

47. Chapman SC, Collignon J, Schoenwolf GC, Lumsden A. Improved method for chick wholeembryo culture using a filter paper carrier. Dev Dyn. 2001; 220:284-9. [PubMed: 11241836]

48. Dono R, Texido G, Dussel R, Ehmke H, Zeller R. Impaired cerebral cortex development and blood pressure regulation in FGF-2-deficient mice. EMBO J. 1998; 17:4213-25. [PubMed: 9687490]

49. Warner DR, Smith HS, Webb CL, Greene RM, Pisano MM. Expression of Wnts in the developing murine secondary palate. Int J Dev Biol. 2009; 53:1105-12. [PubMed: 19598129]

50. Kubota Y, Ito K. Chemotactic migration of mesencephalic neural crest cells in the mouse. Dev Dyn. 2000; 217:170-9. [PubMed: 10706141] 
51. Ortega S, Ittmann M, Tsang SH, Ehrlich M, Basilico C. Neuronal defects and delayed wound healing in mice lacking fibroblast growth factor 2. Proc Natl Acad Sci U S A. 1998; 95:5672-7. [PubMed: 9576942]

52. Boldajipour B, Mahabaleshwar H, Kardash E, Reichman-Fried M, Blaser H, Minina S, et al. Control of chemokine-guided cell migration by ligand sequestration. Cell. 2008; 132:463-73. [PubMed: 18267076]

53. Dambly-Chaudiere C, Cubedo N, Ghysen A. Control of cell migration in the development of the posterior lateral line: antagonistic interactions between the chemokine receptors CXCR4 and CXCR7/RDC1. BMC Dev Biol. 2007; 7:23. [PubMed: 17394634]

54. Valentin G, Haas P, Gilmour D. The chemokine SDF1a coordinates tissue migration through the spatially restricted activation of Cxcr7 and Cxcr4b. Curr Biol. 2007; 17:1026-31. [PubMed: 17570670]

55. Zabel BA, Wang Y, Lewén S, Berahovich RD, Penfold MET, Zhang P, et al. Elucidation of CXCR7-mediated signaling events and inhibition of CXCR4-mediated tumor cell transendothelial migration by CXCR7 ligands. J Immunol. 2009; 183:3204-11. [PubMed: 19641136]

56. Sun Y, Cheng Z, Ma L, Pei G. $\beta$-arrestin2 is critically involved in CXCR4-mediated chemotaxis, and this is mediated by its enhancement of p38 MAPK activation. J Biol Chem. 2002; 277:492129. [PubMed: 12370187]

57. Raz E, Mahabaleshwar H. Chemokine signaling in embryonic cell migration: a fisheye view. Development. 2009; 136:1223-9. [PubMed: 19304885]

58. Thelen M, Stein JV. How chemokines invite leukocytes to dance. Nat Immunol. 2008; 9:953-9. [PubMed: 18711432]

59. Theveneau E, Marchant L, Kuriyama S, Gull M, Moepps B, Parsons M, et al. Collective chemotaxis requires contact-dependent cell polarity. Dev Cell. 2010; 19:39-53. [PubMed: 20643349]

60. Kabashima K, Sugita K, Shiraishi N, Tamamura H, Fujii N, Tokura Y. CXCR4 engagement promotes dendritic cell survival and maturation. Biochem Biophys Res Commun. 2007; 361:1012-6. [PubMed: 17679142]

61. Lataillade JJ, Clay D, Bourin P, Herodin F, Dupuy C, Jasmin C, et al. Stromal cell-derived factor 1 regulates primitive hematopoiesis by suppressing apoptosis and by promoting $G(0) / G(1)$ transition in CD34(+) cells: evidence for an autocrine/paracrine mechanism. Blood. 2002; 99:1117-29. [PubMed: 11830456]

62. Imitola J, Raddassi K, Park KI, Mueller FJ, Nieto M, Teng YD, et al. Directed migration of neural stem cells to sites of CNS injury by the stromal cell-derived factor 1alpha/CXC chemokine receptor 4 pathway. Proc Natl Acad Sci USA. 2004; 101:18117-22. [PubMed: 15608062]

63. Sapède D, Rossel M, Dambly-Chaudière C, Ghysen A. Role of SDF1 chemokine in the development of lateral line efferent and facial motor neurons. Proc Natl Acad Sci USA. 2005; 102:1714-8. [PubMed: 15659553]

64. McLennan R, Teddy JM, Kasemeier-Kulesa JC, Romine MH, Kulesa PM. Vascular endothelial growth factor (VEGF) regulates cranial neural crest migration in vivo. Dev Biol. 2010; 339:11425. [PubMed: 20036652] 
- Failure of embryonic neural crest cell (NCC) migration can cause orofacial clefts.

- We examine the role of SDF-1/CXCR4 signaling in mesencephalic NCC migration.

- Transwell culture and bead implantation in avian embryos provide quantitative data.

- The CXCR4 antagonists, AMD3100 and TN14003, inhibit NCC migration.

- $\quad$ SDF-1/CXCR4 signaling is, thus, required for the migration of mesencephalic NCCs. 

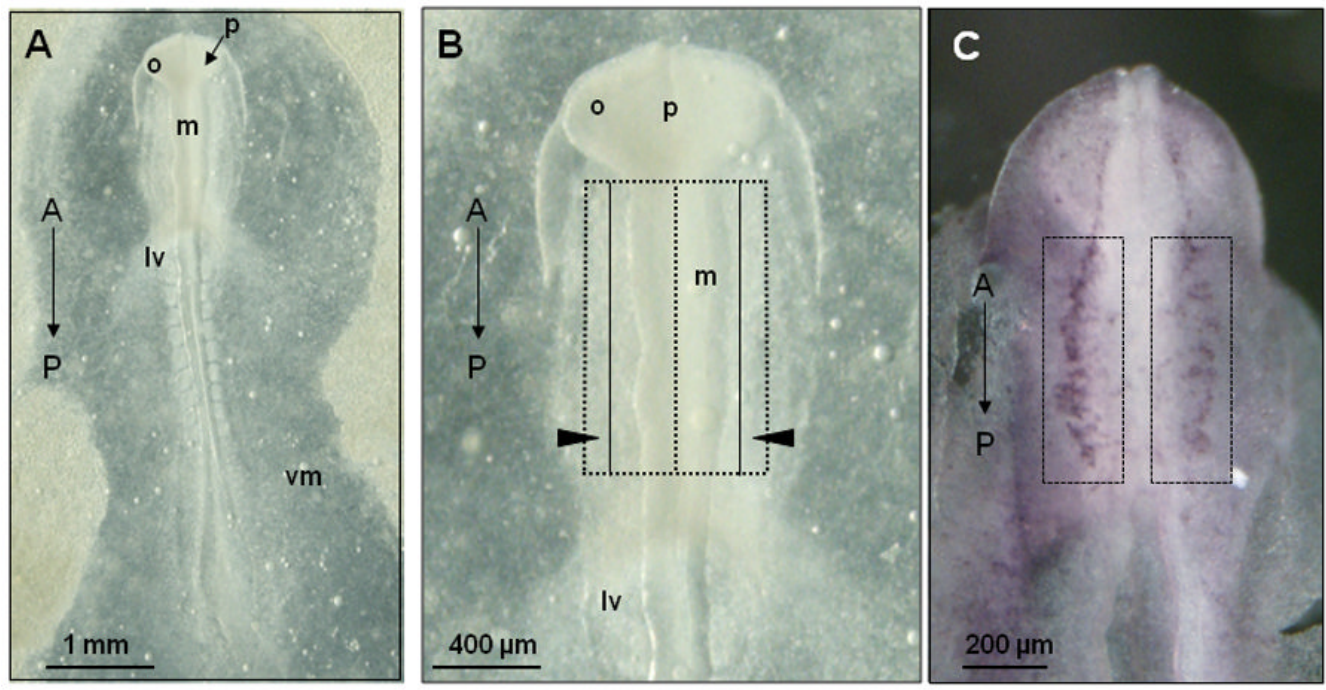

Figure 1. Dissection of mesencephalic (cranial) NC from stage HH 10-11 chick embryos A. Dorsal view of a 13-somite chick embryo surrounded by vitelline membrane $\mathbf{B}$. Higher magnification image of embryo shown in Panel A illustrating the dissection of tissue containing the mesencephalic NCCs. Dissecting needles were used to cut posterior to the optic vesicles (o), then anterior to the presumptive left ventricle (lv) and finally down the mid-line of the mesencephalic neural tube. The two lateral flaps of tissue thus formed were flattened out (as shown by the dotted lines) and the dorsal most edges corresponding to the NCC region (indicated by arrowheads) were microdissected away from the intervening ventral tissue. Cells dissociated from this tissue were used for transwell NCC migration assays. C. Chick embryo (11 somites) immunostained with anti-HNK-1 antibody to localize migratory NCCs (outlined by dotted lines). A $\rightarrow \mathrm{P}$, anterior-posterior axis; $1 \mathrm{v}$ - left ventricle; $\mathrm{m}$ - mesencephalon; $\mathrm{o}$ - optic vesicle; $\mathrm{p}$ - prosencephalon; vm - vitelline membrane. 

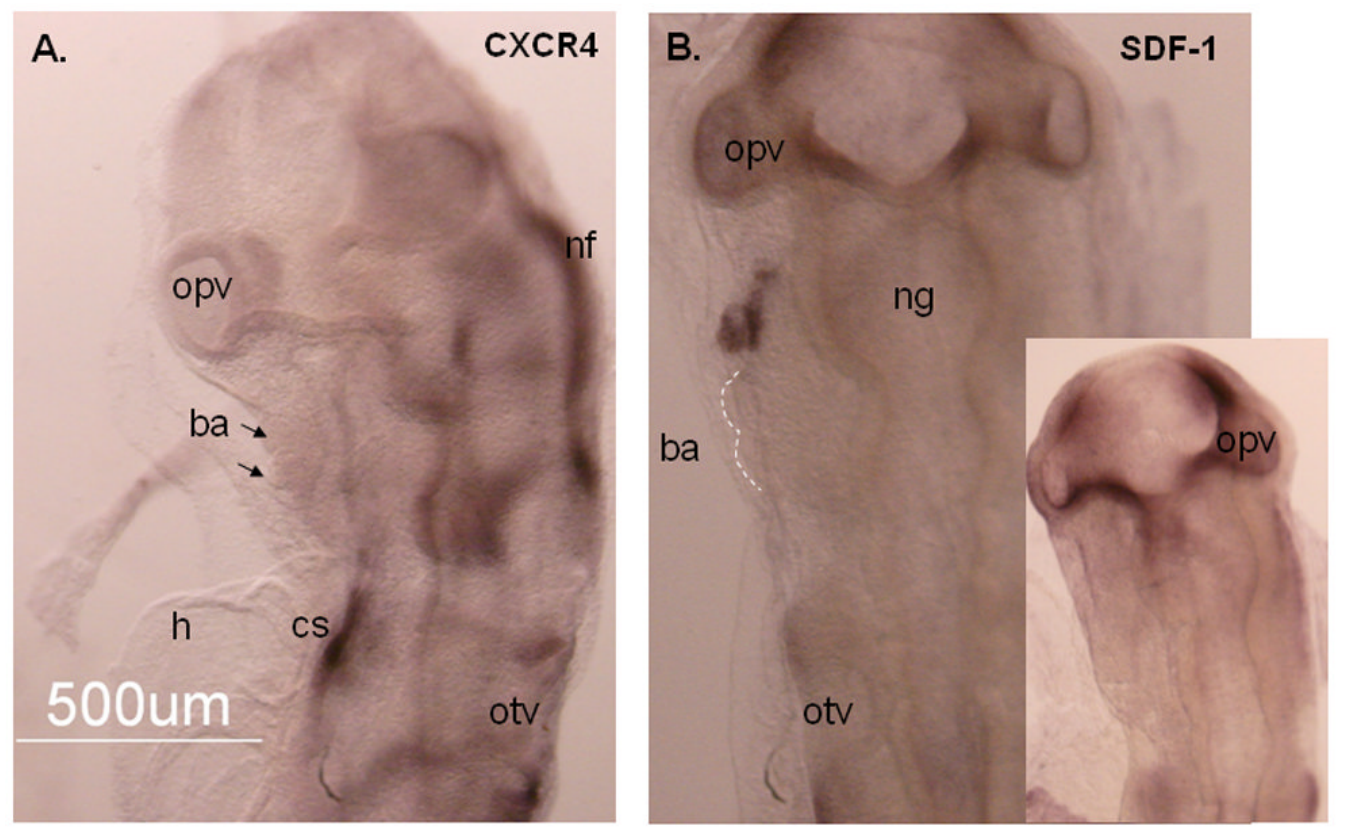

Figure 2. Expression of SDF-1 and CXCR4 in the cranial region of the chick embryo at the time of NCC migration

Chick embryos (HH 9-10) were analyzed for the presence of CXCR4 (A) and SDF-1 (B) expression using in situ hybridization. A. Lateral view of the embryo showing the presence of CXCR4 mRNA at the edge of the neural fold (nf) and streams of CXCR4-expressing cells in apparent transit to the ventral regions of the embryo. B. Dorsal and ventral (inset) views of a HH 9-10 embryo with diffuse $S D F-1$ mRNA expression in the cranial region. ba: branchial arches; nf: neural fold; ng: neural groove; opv: optic vesicle; otv: otic vesicle; h: heart; cs: cardiac septum. 


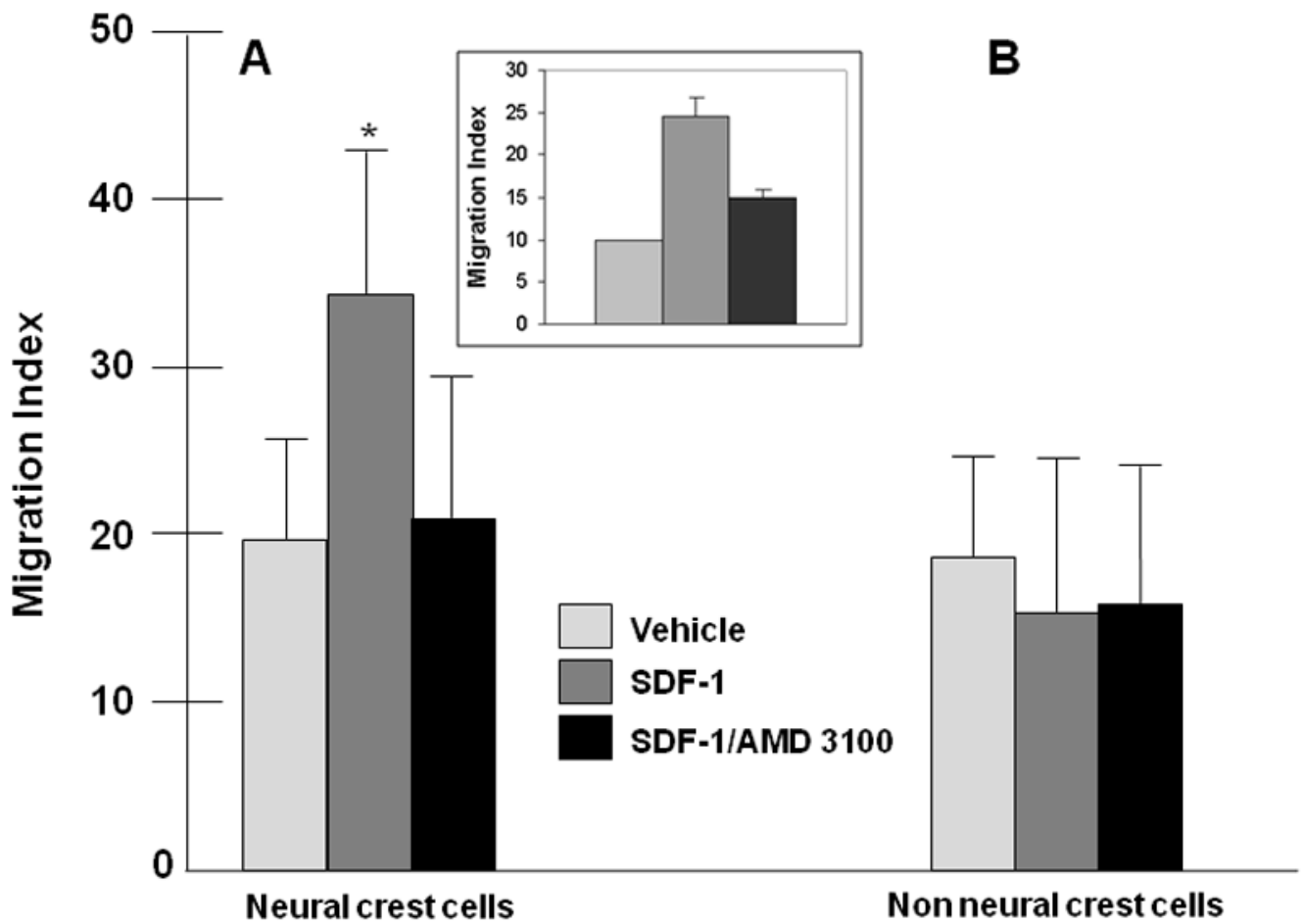

Figure 3. SDF-1 promotes cranial NCC migration in vitro

A. The chemotactic activity of SDF-1 towards NCCs was assessed in transwell migration assays. $3 \times 10^{4}$ cells in DMEM/F12 were seeded into the upper chamber of each transwell. Either SDF-1 $(100 \mathrm{ng} / \mathrm{ml})$ or vehicle (water) was added to the lower chamber of each transwell. In some cases, the CXCR4 antagonist - AMD3100 $(40 \mu \mathrm{M})$ - was added to the upper chamber and SDF-1 $(100 \mathrm{ng} / \mathrm{ml})$ was added to the lower chamber of the transwell. The migration index (MI) was determined from the ratio of the percentage of migrated NCCs to total (unmigrated + migrated) NCCs using HNK-1 immunofluorescence as a NCC marker (see Section 2.1). The data represents the mean of 4 independent biological experiments, each repeated in triplicate. A 1.8-fold increase in NCC migration is seen with SDF-1 (*, p $<0.03)$. Shown in the inset is a representative data from a single experiment. $\mathbf{B}$. The effect of SDF-1 on the MI of the non-NCC mesencephalic cell population is depicted. The number of non-NCCs was determined by subtracting the number of HNK-1 positive NCCs from the total number of cells in the population. DAPI staining of cellular DNA was used to determine the total cell number. Experimental details are the same as in Panel A. No significant chemotactic effect of SDF-1 is seen on non-NCCs. 

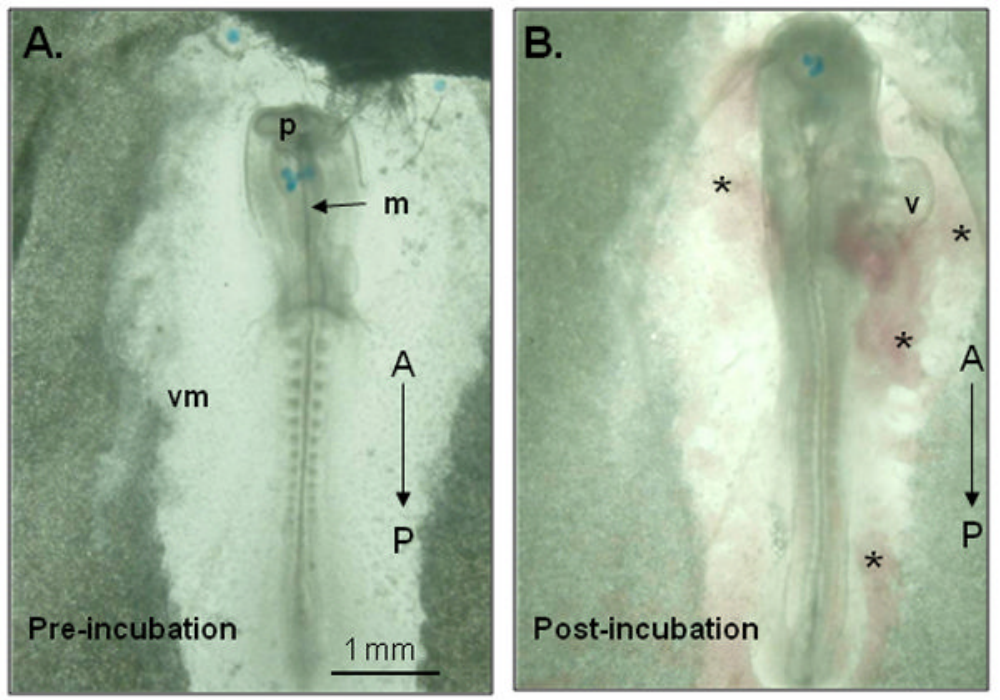

Figure 4. A chick embryo, ex ovo, with vehicle (BSA)-soaked agarose beads implanted into the developing cranial neural tube; pre- and post-culture

A. Dorsal view of an intact $\mathrm{HH} 10-11$ chick embryo on saline/agar/albumin substrate prior to overnight culture at $37^{\circ} \mathrm{C}$. Agarose beads (blue spheres) soaked with $10 \mathrm{mg} / \mathrm{ml} \mathrm{BSA}$ were implanted into the mesencephalic dorsal neural tube $(\mathrm{m})$ just posterior to the prosencephalon (p). B. The same chick embryo after overnight incubation had developed to stage HH 12. Note normal development of the cardiac ventricle (v), the overall growth of the embryo, and the initial vascularization (asterisks) of the vitelline membrane (vm). $1 \mathrm{~mm}$ size bar applies to both panels. $\mathrm{A} \rightarrow \mathrm{P}$ indicates anterior-posterior axis. 

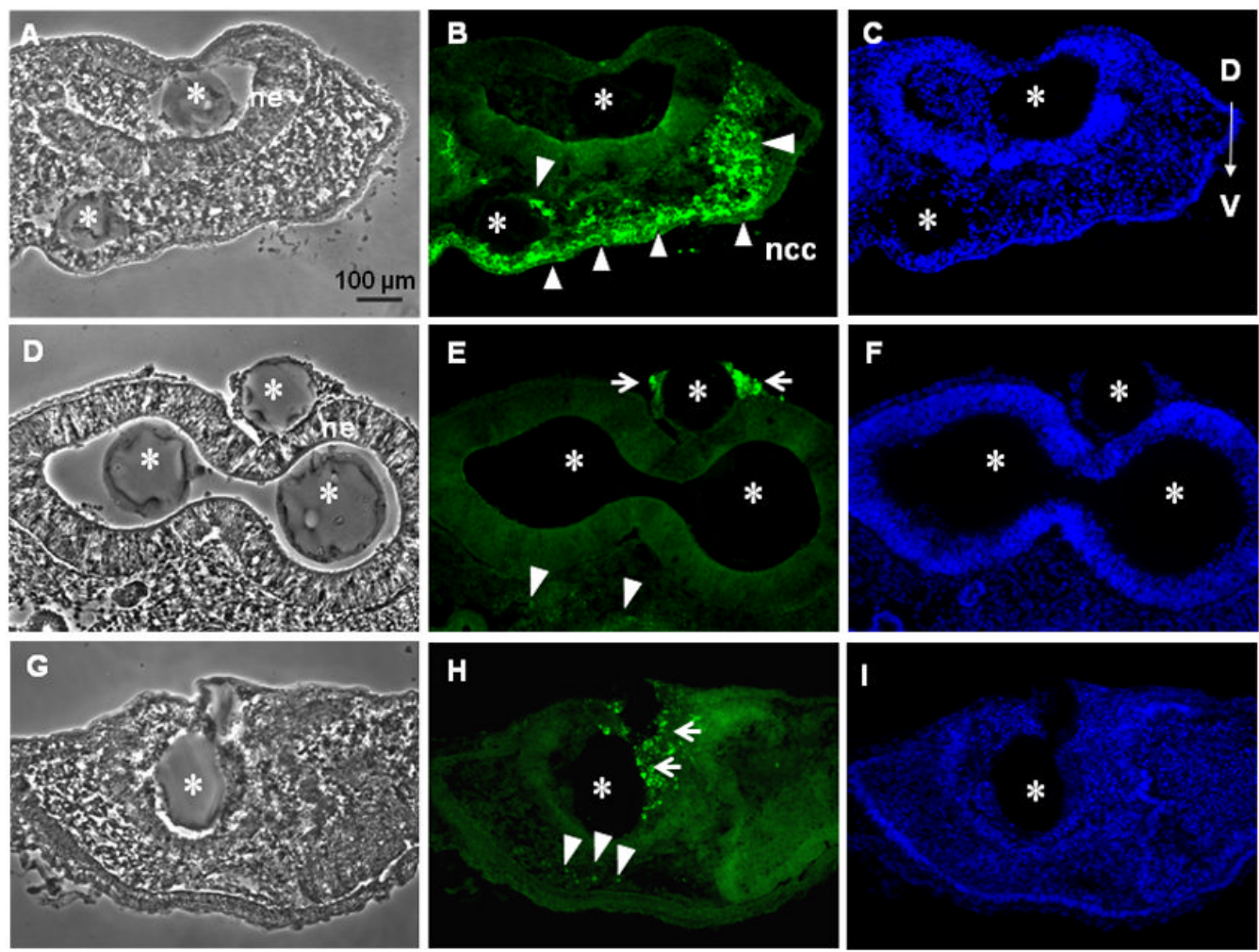

Figure 5. Inhibition of endogenous SDF-1 signaling in chick embryo culture disrupts mesencephalic NCC migration

Chick embryos that had been implanted with TN14003- or BSA-soaked beads (as described in the legend for Fig. 4) were cryosectioned, immunostained with anti-HNK-1 antibody and counterstained with DAPI. Panels show transverse sections from cryosectioned chick embryos that were implanted with agarose beads (asterisks) soaked with either $10 \mathrm{mg} / \mathrm{ml}$ BSA (A-C), or $10 \mathrm{mg} / \mathrm{ml}$ TN14003 (D-F; G-I). Sections were photographed using brightfield optics (A, D, G), epifluorescence optics to visualize HNK-1 immunostaining (Alexa Fluor-488; 496 nm/519 nm) (B, E, H), and epifluorescence optics to visualize nuclear staining (DAPI; 350nm/460nm) (C, F, I). A-C: Transverse sections from a representative cultured chick embryo with BSA- implanted beads (asterisks). NCCs (arrowheads; B) have emerged and migrated from the dorsal aspect of the neural folds to the ventral mesenchyme. D-F and G-I: Transverse sections from two different representative cultured chick embryos with TN14003-implanted beads (asterisks). Note that the antagonist soaked beads have inhibited the migration of most of the NCCs to the ventral mesenchyme, localizing the cells to the vicinity of the beads (arrows; $\mathbf{E}, \mathbf{H}$ ). A small number of NCCs that have escaped this inhibition are also apparent (arrowheads at the ventral aspect of the embryo; $\mathbf{E}, \mathbf{H})$. D $\rightarrow \mathrm{V}$ (dorsal to ventral axis) and the $100 \mu \mathrm{m}$ size bar applies to all panels. ncc: neural crest cells; ne: neuroepithelium. 


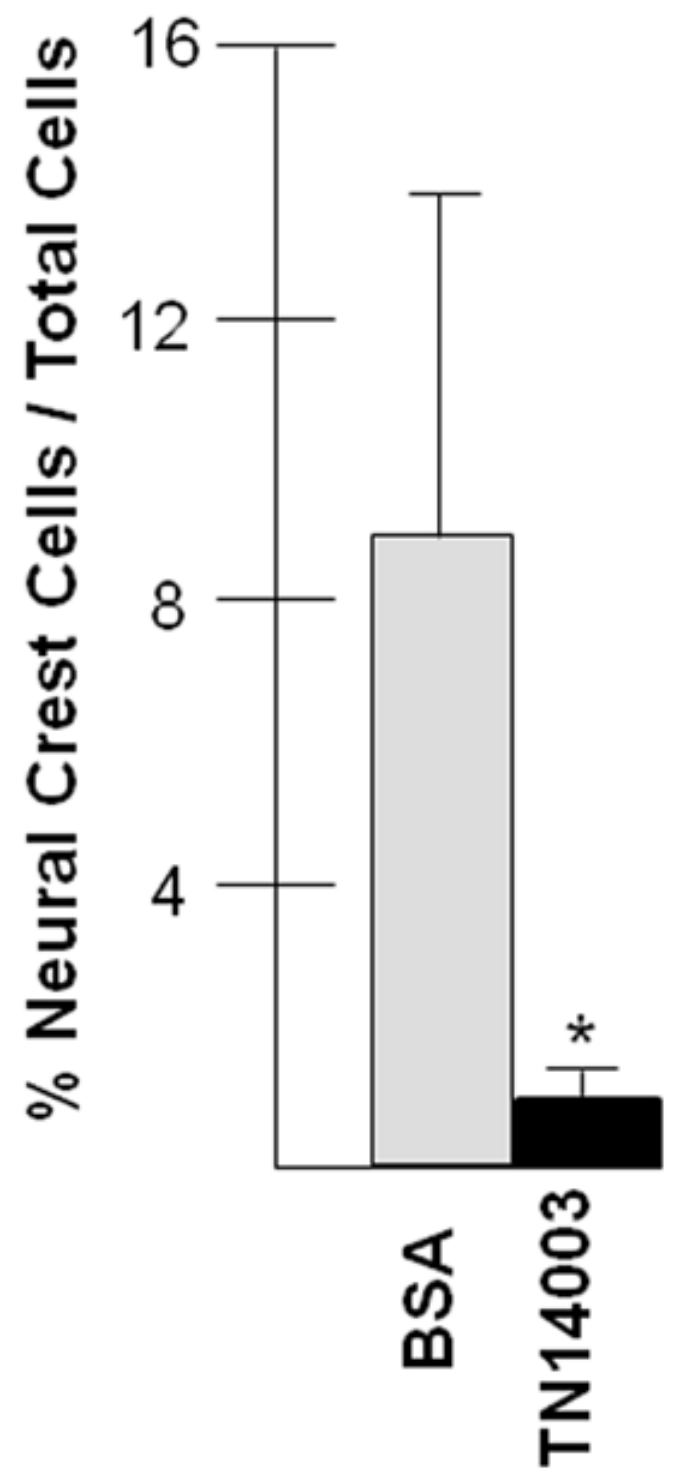

Figure 6. Effect of TN14003-soaked bead implantation on mesencephalic NCC migration in chick embryos cultured ex vivo

Sections from BSA- or TN14003- treated chick embryos taken at equivalent positions along the anterior-posterior axis were compared to determine the percentage of migrating mesencephalic cells that were NCCs. The total area of HNK-1 fluorescence (NCCs) in 6 sections from each embryo was expressed as a percentage of the DAPI fluorescence (total cells) from the same 6 sections. A total of 4 chick embryos each was used for BSA and TN14003 treatments. An 86\% reduction (*, p<0.03) in migrating NCCs was observed in embryos with implanted TN14003-soaked beads. 

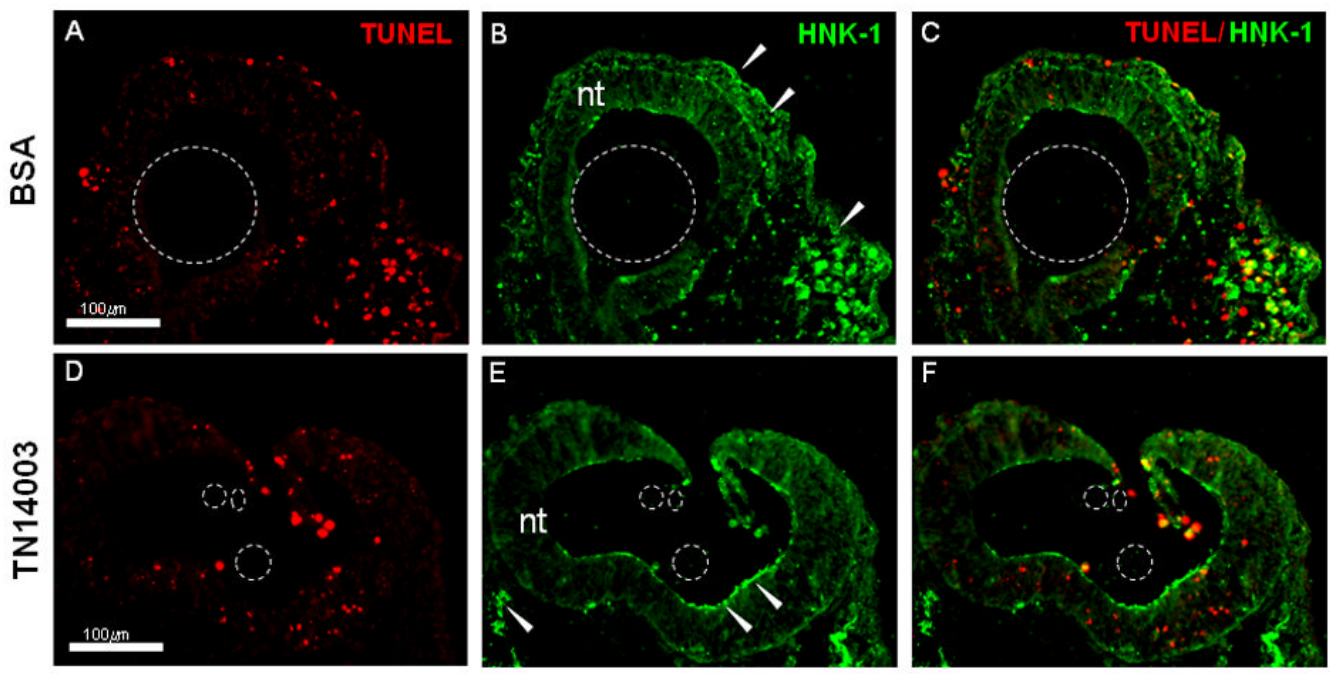

Figure 7. Effect of TN14003-soaked bead implantation on mesencephalic NCC apoptosis in chick embryos

Sections from BSA- (A-C) or TN14003- (D-F) treated chick embryos taken at equivalent positions along the anterior-posterior axis in the mesencephalic area were labeled for evaluation of apoptosis. Apoptosis was determined using a TUNEL assay $(\mathbf{A , D})$ in association with HNK-1 fluorescence localization of NCC (B,E), with the merged photomicrographs shown in $\mathbf{C}$ and F. Arrowheads identify NCCs and dashed lines delineate the location of the beads. nt: neural tube. Note that a significant proportion of NCCs are trapped in the lumen of the neural tube in TN14003-treated embryos (arrowheads, E) compared to BSA-treated embryos wherein NCCs have migrated from the dorsal aspect of the neural folds, and are apparent outside the neural tube (arrowheads, B). The $100 \mu \mathrm{m}$ scale applies to all panels. 

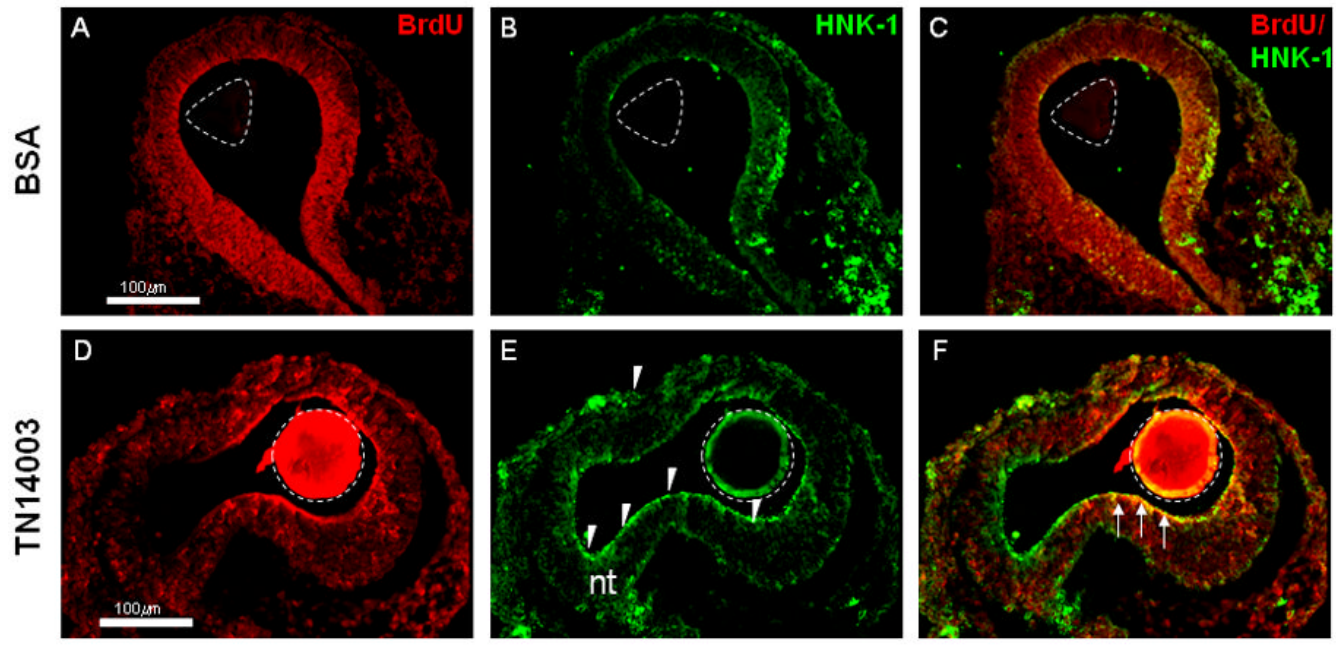

Figure 8. Effect of TN14003-soaked bead implantation on mesencephalic NCC proliferation in chick embryos

Sections from BSA- (A-C) or TN14003- (D-F) treated chick embryos taken at equivalent positions along the anterior-posterior axis in the mesencephalic area were labeled for evaluation of proliferation. Proliferation was determined using a BrdU incorporation assay. An anti-BrdU antibody was used to immunolocalize BrdU in proliferating cells (A,D) and an anti-HNK-1 antibody to identify NCC (B,E). Panels $\mathbf{C}$ and $\mathbf{F}$ show proliferating NCC in the merged photomicrographs. In Panels A through F, arrowheads identify NCCs, dashed lines delineate the location of the beads, and the arrows (in F) indicate BrdU positive NCCs. nt: neural tube. Note that a significant proportion of NCCs are trapped in the lumen of the neural tube in TN14003-treated embryos (arrowheads, E) compared to BSA-treated embryos wherein NCCs have migrated from the dorsal aspect of the neural folds and are apparent outside the neural tube (arrowheads, B). The $100 \mu \mathrm{m}$ scale applies to all panels. 